\title{
Literatura Latino-americana contemporânea: perspectivas desconstrucionistas e decoloniais de heróis - projetos de leitura crítica
}

\author{
Latin American Contemporary Literature: desconstructionist and decolonial perspectives \\ of heroes - critical reading projects
}

\author{
Ana Maria Klock* \\ Universidade Estadual do Oeste do Paraná \\ Cascavel, Paraná, Brasil \\ Hugo Eliecer Dorado Mendez ${ }^{* *}$ \\ Universidade da Integração Latino-americana \\ Foz do Iguaçu, Paraná, Brasil
}

\begin{abstract}
Resumo: A figura de Simón Bolívar tem sido reconfigurada, na literatura, a partir de diversas perspectivas que ora convergem com o discurso oficial da história ora divergem em distintos níveis e com distintas intenções ideológicas. A relevância dos feitos do Libertador transcende até os dias atuais e o impacto do legado bolivariano - de luta e resistência, mas, também, de corrupção e autoritarismo - repercute nos cenários nacionais dos países destas terras e deveria chegar ao espaço da sala de aula. Igualmente ocorre com a figura histórica do Imperador do Brasil: D. Pedro I. Na literatura contemporânea latino-americana das últimas décadas encontramos romances híbridos de história e ficção que, por meio de singulares estratégias discursivas, narrativas e escriturais, arquitetam uma figura de Bolívar integralmente desconstruída, abandonando qualquer tipo de indulgência outorgada a respeito dos seus feitos mais questionáveis. Uma dessas obras é escrita por Herbert Morote, pesquisador e literato peruano, La visita de Bolivar (2018). Tal processo também ocorre com D. Pedro I na obra Galantes memórias e admiráveis aventuras do virtuoso conselheiro Gomes, o Chalaça (1994), de Roberto Torero. No presente estudo buscamos, por meio da análise estética e discursiva dessas obras, compreender o processo de desmistificação e desconstrução do qual as figuras históricas são foco para revelar a importância destas obras na trajetória formativa de um leitor crítico. Evidenciamos, também, como esse processo de revisão e ressignificação histórica aponta para novos caminhos dentro dos estudos decoloniais, visando a uma reestruturação ideológica e social no nosso continente. Para tanto, apoiamo-nos nos pressupostos de Mignolo (2007), Fleck (2017) e Menton (1993), entre outros pesquisadores nas áreas da teoria decolonial, do romance histórico na América Latina e dos processos de ressignificação da história pela literatura contemporânea.
\end{abstract}

Palavras-chave: Simón Bolívar. D. Pedro I. Ressignificação da história. Estudos decoloniais. Ensino de literatura.

\footnotetext{
${ }^{*}$ Mestra e doutoranda em Literatura pela Unioeste-Cascavel-PR, Bolsista CAPES. E-mail: anamariaklock@hotmail.com.

${ }^{* *}$ Mestrando em Literatura pela UNILA-Foz do Iguaçu-PR, Bolsista CAPES. E-mail: felipebemol@hotmail.com.
} 


\begin{abstract}
Simon Bolívar's figure has been reconfigured in Literature from different perspectives in which his images sometimes converge with the official discourse of History and sometimes diverge from them in distinct levels and with different ideological purposes. The relevance of the Liberator's achievements transcends to the present days and the impact of the Bolivarian legacy - of struggle and resistance, but also of corruption and authoritarianism - reflect in the national scenarios of the countries of these lands and this should get to the classroom space. It also occurs with the historical figure of the Emperor of Brazil: D. Pedro I. In the Latin-American contemporary Literature, we find in the last decade hybrid novels of History and fiction that, through unique discursive, narrative and writing strategies, architect a fully deconstructed figure of Bolívar, abandoning in the narrative tissue any kind indulgence regarding his most questionable deeds. One of this work is La visita de Bolivar (2018), written by Herbert Morote, Peruvian researcher and novelist. The same process also occurs with D. Pedro I in the novel Galantes memórias e admiráveis aventuras do virtuoso conselheiro Gomes, o Chalaça (1994), by Roberto Torero. By the aesthetic and discursive analysis of this novel, we aim to understand the demystification and deconstruction process that these historical figures are the focus of to reveal the importance of this works in the formative trajectory of a critical reader. We also highlight how this historical revision and remeaning of the past points to new paths within decolonial studies aiming for an ideological and social restructuration in our continent. For this purpose, we based our study upon the theories by Mignolo (2007), Fleck (2017) and Menton (1993), among others researchers in the area of the decolonial theories, historical novel in Latin America and process of remeaning of History by contemporary Literature.
\end{abstract}

Keywords: Simón Bolívar. Remeaning of History. Decolonial Studies. Literature teaching.

\title{
1 INTRODUÇÃO
}

No contexto do ensino da Literatura Hispano-americana, vemos que, em torno à figura de Bolívar, o acervo de produções de literatura híbrida de história e ficção é amplo e abarca muitas das modalidades do gênero romance histórico. Assim, podemos encontrar, para exemplificar a diversidade dessa expressão literária aos estudantes, tanto obras que idealizam a sua figura de supremo Libertador e forjador das nações livres da América do Sul - como Las lanzas coloradas (1930), do venezuelano Arturo Uslar Pietri, Cérebro e Coração de Bolivar (1930), do brasileiro Sylvio Julio, ou En busca de Bolivar (2010), do colombiano Willian Ospina -, como obras que humanizam e desmitificam a sua figura em distintos níveis - como La ceniza del Libertador (1987) e El general en su Laberinto (1989) - até obras que a desconstroem e carnavalizam severamente - como La carroza de Bolivar (2012) ou La visita de Bolivar (2018).

Como professores é relevante mostrar aos estudantes que, embora ainda persistam algumas ocorrências de romances históricos tradicionais, que exaltam a figura do Libertador tal e como foi exposta no discurso historiográfico oficializado dos países da nossa parte do continente (principalmente da Venezuela, Colômbia, Equador, Bolívia e Peru), a tendência desde o período da nova narrativa latino-americana, no qual se insere o boom da nossa literatura, nas décadas de 1960 e 1970, é o questionamento a esse discurso hegemônico. Podem ser apoio para isso as declarações que expõem Ricardo Oviedo, em sua obra Simón Bolivar como personaje literário en la novela y otras ficciones colombianas (2015), e Juan Galvez, em La figura histórica de Simón Bolivar en la literatura colombiana (2018). Ambos estudiosos apontam para a transformação das perspectivas pelas quais o passado é revisitado e relido pela ficção na literatura colombiana, o que produz uma ressignificação da figura de Bolívar, a qual é retirada do pedestal da consagração para ser humanizada, desmistificada e/ou carnavalizada. 
Nas últimas décadas se intensificou o uso da ficção como meio de explorar e buscar "entre las ruinas de una historia desmantelada al individuo perdido por detrás de los acontecimentos" (AÍNSA, 1991, p. 85), e, ainda, como ferramenta de descolonização, pois, como destaca Fleck (2017, p. 127),

[a]o reinventar o passado - incorporando ao tecido narrativo muitas das escritas oficiais pela intertextualidade e pela paródia, dando um tratamento carnavalizado à configuração dos heróis instituídos pelo discurso historiográfico -, o romance histórico, em suas vertentes críticas, reterritorializa esse espaço com perspectivas pluralizadas dos fatos passados.

Essa tendência por uma produção crítica, questionadora e, por vezes, denunciadora no gênero romance histórico ao redor da figura de Bolívar não se restringe ao contexto intelectual da Colômbia, como demonstramos a seguir. A onda desconstrucionista ao redor do grande herói da independência se estende pelos territórios cuja ferida colonial, segundo Walter Mignolo (2007), ainda permanece aberta. Tal perspectiva crítica de nossa literatura merece lugar de destaque na sala de aula.

Assim, no presente estudo, abordamos uma dessas obras que estabelecem a releitura da figura e dos feitos de Bolívar: La visita de Bolivar (2018), do peruano Herbert Morote, como modelo para o ensino de literatura crítica nos cursos de graduação, em especial de Língua e Literatura Espanhola. Buscamos, por meio da análise estética da obra, verificar os processos de desconstrução da figura histórica, dando ênfase às estratégias escriturais utilizadas em tal construção discursiva dentro da tessitura narrativa, procedimento que os professores podem adotar na leitura coletiva da obra entre os alunos. Visamos, ademais, a evidenciar a intenção crítica da ficção a respeito da história oficial, apontando, principalmente, para o paradigma da colonialidade, ao qual Simón Bolívar, embora ilustre independentista, permaneceu estreitamente vinculado. Assim, a literatura revela outros vieses do passado que podem ser abordados em sala aula.

Visto o processo de desconstrução feita com o herói das independências hispanoamericanas, projetamos essas mesmas intenções críticas à ressignificação da história do Brasil efetuado na obra Galantes memórias e admiráveis aventuras do virtuoso conselheiro Gomes, o Chalaça (1994), de Roberto Torero. O Imperador do Brasil foi, assim como Bolívar, personagem histórica celebrada pela ficção, em obras exaltadoras como as de Paulo Setúbal, em especial no romance As Maluquices do Imperador (1927) para, com o passar das décadas enfrentar-se com releituras críticas de autores comprometidos com a descolonização ainda necessária em nosso país, como evidenciamos na sequência.

\footnotetext{
1 Tradução livre: entre as ruinas de uma história desmantelada o indivíduo por trás dos acontecimentos.
} 


\section{A LITERATURA COMO OUTRA POSSÍVEL ABERTURA AO PASSADO: LA VISITA DE BOLÍVAR (2018) - O "LIBERTADOR" NA PERSPECTIVA CRÍTICA DO ROMANCE HISTÓRICO PERUANO}

O romance que abordamos nesta parte do presente estudo, sendo modelo crítico de escrita híbrida de história e ficção, como sugestão ao ensino de Literatura Hispanoamericana, La visita de Bolivar (2018), é a adaptação ao gênero romanesco de uma peça teatral com o mesmo título. $O$ romance histórico e a peça, lançados quase simultaneamente, não diferem como texto; os diálogos e as ações da peça são mantidos no romance, sempre que possível. Temos de destacar, no entanto, que existem notáveis diferenças de um gênero para outro, dada a sua natureza artística composicional. O romance nos permite adentrar na psique das personagens, com as detalhadas impressões do narrador heterodiegético; enquanto a peça de teatro conta com a expressividade e a performance dos artistas-personagens, denotando o tom das vozes, os movimentos e, ainda, os silêncios. Estas e tantas outras divergências podem ser destacadas numa análise mais aprofundada sobre ambas as obras junto aos alunos, não obstante, não é o nosso intuito realizar tal labor investigativo, pois, aqui, buscamos nos centramos no romance histórico, focalizando as estratégias narrativas próprias da escrita híbrida de história e ficção.

O enredo da obra inicia na casa de Bernardo Monteagudo - personagem de extração histórica - assessor de Bolívar no Peru. É o dia 25 de janeiro de 1825, numa sexta-feira à noite, como se explicita no início do romance. A cidade de Lima, onde se desenvolvem os acontecimentos narrados, permanece num estado espectral e sombrio, "quedó atrás esa Lima parrandera, vivaracha y frívola donde tanto señores como criados se divertían sin decoro y con vehemencia." (MOROTE, 2018, p. 9). Tal situação é decorrente da chegada das tropas bolivarianas que, após a Batalla de Ayacucho "están acantonadas en Lima y se creen dueños del Perú.” (MOROTE, 2018, p. 9).

Monteagudo espera a visita de uma dama para passar uma aprazível noite com pretensões amorosas, para tanto, o seu mordomo Lucero - personagem puramente ficcional -, antigo escravo negro que agora conta com uma suposta liberdade perante a lei, ajuda-lhe nos preparativos: champanhe, livros de poesia etc. O visitante que irrompe de imprevisto na sua casa, no entanto, é nada menos do que Bolívar, figura de máxima autoridade no contexto político e militar de então. A surpresa causada a Monteagudo e ao seu mordomo é singular, pois, além do evidente sobressalto da visita do homem que poderia em qualquer momento e por qualquer motivo "mandar fuzilar" a ambos, existia mais um agravante: a mulher que o assessor esperava era Manuelita Sáenz, "la amante oficial del Libertador" ${ }^{4}$ (MOROTE, 2018, p. 22). A chegada de Bolívar, estrepitosa e violenta, em sentido figurado, é bem manejada por Monteagudo, o qual convida o General a ficar na sua casa para jantar e conversar o resto da noite. A conversa entre as

\footnotetext{
2 Tradução livre. "ficou atrás essa Lima festiva, jocosa e frívola onde tanto senhores como criados se divertiam sem decoro nem veemência.

3 Tradução livre: estão acantonados em Lima e creem ser donos do Peru.

4 'Tradução livre: a amante oficial do Libertador.
} 
duas personagens, com pequenas intromissões de Lucero, estende-se, oportunizando, nos diálogos ficcionais, espaços para a criticidade histórica.

Nozad Heshmat Kasem ${ }^{5}$ (2018), num dos poucos trabalhos desenvolvidos ao redor do romance de Morote, aponta para umas das possíveis interpretações do título da obra. Para a professora, o título não só explicita a visita de Bolívar a Monteagudo no romance, mas, também, "puede ser un simbolo de la visita de Bolivar a Perú. Las dos visitas terminan trágicamente." (HESHMAT KASEM, 2018, s/p.). Nessa linha de pensamento, planteia-se uma possível alegoria do contexto social, político e militar do Peru no singular ato da visita de Bolívar a Monteagudo. Ao seguir esse raciocínio, podemos compreender a disposição temporal e espacial das ações no romance como uma estratégia narrativa para plasmar, na ficção, o conflito social que se vivia então: uma noite escura e sombria de Lima, como todas as noites desde que o exército libertador chegara à cidade; ruas abandonadas por famílias "que abandonaron el país o se escondieron en sus haciendas" ou que, "por temor a los asaltos ni siquiera [...] van a los velorios." (MOROTE, 2018, p. 9).

A chegada do General, violenta e estrepitosa, é bem descrita pelo narrador, o qual dá ênfase ao fato de Bolívar buscar, desde o primeiro momento, tomar posse do lugar e da situação, exercendo "un juego de poder [...] para establecer relaciones de dominio." (HESHMAT KASEM, 2018, s/p). Vejamos:

El Libertador da unos pasos en la sala y sin mirar a Monteagudo lanza una mirada rápida al entorno.

- ¡Qué bonito departamento! - exclama, y sin más se quita el sombrero e intenta dárselo a Monteagudo que se ha puesto de pie. No es la primera vez que Monteagudo ve a Bolívar tener gestos como este. Desde que aparece, el Libertador siempre hace o dice algo para mostrar su superioridad, su rango. (MOROTE, 2018, p. 15).

Após o momento inicial de tensão, como dito, Monteagudo consegue manobrar a situação. Bolívar, que já demostrava intenções de discutir certos temas de relevância com seu assessor, mas que aparentava querer ir embora ao perceber que este esperava a visita de uma mulher, decide ficar. A conversação entre ambos, não obstante, estará marcada, do princípio ao fim, por uma desconfiança mútua, um duelo de interlocutores que medem suas palavras, gestos e silêncios para não desvelar suas cartas. As personagens, no entanto, terão, nesse embate discursivo, um posicionamento claro, isto é, serão dispostas ficcionalmente em papeis determinados: Bolívar como a figura agressiva e assaltante que procura motivos para desconfiar da lealdade absoluta do seu assessor, sua presa - "se me está escapando la presa, piensa Bolivar, por abí no es el camino. Hay que cambiar la dirección"” (MOROTE, 2018, p. 25) -; e Monteagudo como o cauteloso e

${ }^{5}$ Professora doutora atuante no Departamento de Lengua y Literatura Hispánicas da Facultad de Letras, na Universidad de El Cairo.

${ }^{6}$ Tradução livre: pode ser um símbolo da visita de Bolívar a Peru. As duas visitas terminam tragicamente.

7 Tradução livre: que abandonaram o país ou se esconderam nas suas fazendas ou que, por medo aos furtos, nem sequer [...] vão aos velórios.

${ }^{8}$ Nossa tradução livre.

${ }^{9}$ Tradução livre: a presa está fugindo, pensa Bolívar, esse não é o caminho. Tenho de mudar o rumo. 
audaz opositor dos ideais mais absurdos do General - "lo mejor es no caer en su juego, no debo perder las casillas, piensa Monteagudo."10 (MOROTE, 2018, p. 26).

A diegese construída por Morote é tradicional e simples, enquanto a estrutura e composição escritural, isto é, as ações se desenvolvem em forma linear, num só espaço temporal e físico e são narradas numa linguagem coloquial, de fácil compreensão. Tais aspectos auxiliam a leitura por parte de um leitor em formação. A carga discursiva, contudo, é ampla e transita por diversos campos históricos, culturais e sociais em relação à figura de Bolívar e aos seus feitos no Peru, necessitando, assim, da mediação do professor para que o aluno alcance a dimensão pretendida pela releitura crítica da ficção. A leitura entre alunos pode seguir alguns tópicos, como sugerimos à continuação.

\subsection{BOLÍVAR E A QUESTÃO RACIAL NAS NAÇÕES INDEPENDENTES}

Uma das questões levantadas na conversa entre as duas personagens, à qual consideramos deve ser dado destaque, é a problemática racial, racismo, propriamente dito, que impera[va] nas nossas terras desde época do colonialismo. Eis a importância do terceiro elemento imerso na tessitura narrativa: Lucero, o antigo escravo negro. Só a sua presença no espaço ficcional já evoca a intenção pluriperspectivista do romance, mas a sua significância é ainda maior dado aos atributos e ao papel a ele outorgados dentro da diegese criada por Morote.

Lucero é um homem livre, como o resto dos negros peruanos, porém, nessa ambígua liberdade outorgada pela lei, "los negros, que no están seguros si han sido emancipados o no, pululan por la ciudad obligados a delinquir para poder llevarse un pan a la boca"11 (MOROTE, 2018, p. 09). Isto é, apesar dos decretos contra qualquer tipo de subjugação racial promulgados nas nações independentes, a desigualdade absoluta continuava imperando na sociedade, e Lucero era um dos atingidos. Os indígenas, do mesmo modo, permaneciam, mesmo após as independências, submetidos à dominação por parte das elites das distintas regiões, tendo que pagar ainda impostos pela sua cor de pele: "no es justo restablecer el impuesto que pagaban los indígenas al rey de España sólo por ser indios. ¡Hombre, Excelencia, para eso han luchado por su libertad?"12 (MOROTE, 2018, p. 75).

Assim, Lucero, que carrega na sua figura a significação dos povos oprimidos, encontra-se frente a frente com Bolívar, sendo também uma peça chave na noite da visita. Os bons tratos que Monteaguado dava a Lucero permitem-nos asseverar que entre eles, no romance, há certa relação de amizade ou cumplicidade. Já Bolívar, então, é configurado pelo narrador no outro polo desse marco sócio-político.

Por meio da voz da personagem Monteagudo que, junto a San Martin, segundo a historiografia, havia impulsado decretos que facilitavam a emancipação dos negros e dos indígenas no Peru, o romance adquire um tom crítico e denunciador, mostrando como

\footnotetext{
10 Tradução livre: o melhor é não cair no seu jogo, não devo perder o decoro, pensa Monteagudo.

11 Tradução livre: os negros, que não têm certeza de ter sido emancipados, transitam pela cidade obrigados a delinquir para poder levar um pão à boca.

12 Tradução livre: não é justo reestabelecer o imposto que pagavam ao rei de Espanha só por ser índios. Por favor, Excelência, para isso eles lutaram pela sua liberdade!
} 
Bolívar se havia posicionado contra essas determinações. Vejamos, pelos trechos a seguir, como isso é elaborado no romance:

También podría decirle que esas disposiciones cayeron en saco roto cuando Bolívar se hizo con el gobierno del Perú y suspendió de hecho la emancipación automática de los negros vivos o por nacer. Ahora todo eran trabas [...]. ${ }^{13}$ (MOROTE, 2018, p. 19).

Pero mire, yo fui mucho más práctico porque en vez de enemistarme con los propietarios de esclavos, firmé un decreto regulando su posesión y exigiendo un trato humanitario. Eso, querido amigo, es el reflejo de mi bondad y simpatía por los negros. ${ }^{14}$ (MOROTE, 2018, p. 46).

No sabía que usted restablecería el tributo que pagan los indios por ser indios. Con todo respeto, Excelencia, esa decisión me parece la más injusta que ha tomado usted hasta ahora. ${ }^{15}$ (MOROTE, 2018, p. 74).

A desconstrução do perfil benévolo e indulgente de Bolívar para com as raças e povos do nosso continente é perceptível. Tal efeito se dá por meio da exploração do plano histórico dentro do romance, isto é, por meio de asseverações na diegese baseadas na historiografia - como o fato de que Bolívar se opôs ferrenhamente à liberdade absoluta de negros e indígenas, anulando os decretos já promulgados e estabelecendo acordos com os proprietários de escravos.

O processo crítico em torno à questão racial não cessa nessa esfera histórica, mas continua e se reforça com a essência ficcional, como podemos conferir no seguinte fragmento:

- En eso tiene razón, Excelencia, nunca he tenido esclavos como usted. En un momento usted tuvo dos mil, ¿'verdad?"

- Fue una herencia familiar, Monteagudo. Pero no se olvide de que ya les he otorgado la libertad -responde Bolívar tratando de contener su carácter.

Monteagudo sabe que ha tocado un punto débil e insiste:

- Sí, lo sé, pero eso sucedió hace poco. Mucho después de su famosa carta de Jamaica.

- Parece que me está estudiando - contesta con ironía el general - ¿No estará escribiendo mi biografía, eh? Pues tome nota que fui uno de los primeros venezolanos que intentó liberar a sus esclavos, lo que sucedió fue que los negros se negaron porque me amaban. No, no ponga esa cara de incrédulo, Monteagudo, eso es verdad. Al final, y pasados unos años, tuve que forzarlos a emanciparse. ${ }^{16}$ (MOROTE, 2018, p. 47).

\footnotetext{
${ }^{13}$ Tradução livre: Também poderia dizer que essas disposições caíram no esquecimento quando Bolívar tomou posse do governo do Peru e suspendeu de fato a emancipação dos negros vivos e por nascer. Agora tudo eram obstáculos [...].

14 Tradução livre: Porém, olha, eu fui muito mais prático porque ao invés de criar inimizade com os proprietários de escravos, assinei um decreto regulando sua posse e exigindo um trato humanitário. Isso, querido amigo, é o reflexo da minha bondade e simpatia pelos negros.

${ }^{15}$ Tradução livre: Não sabia que você reestabeleceria o tributo que pagam os índios por ser índios. Com absoluto respeito, Excelência, essa decisão me parece a mais injusta que você tomou até agora.

16 Tradução livre: - Nisso tem razão. Excelência, nunca tenho tido escravos como você os teve. Num momento você teve dois mil, verdade? - Foi uma herança familiar, Monteagudo. Mas não esqueça que eu já tinha outorgado a liberdade para eles - responde Bolívar tratando de conter seu caráter. Monteagudo sabe que tocou num ponto fraco e insiste: - Sim, eu sei, mas isso aconteceu faz pouco. Muito tempo após a sua famosa carta de Jamaica. - Parece que está me estudando - responde com ironia o General. Não
} 
No trecho, observamos o audaz movimento discursivo empregado na narrativa. Por meio de uma conversa verosímil entre Bolívar e seu assessor, cria-se a oportunidade de reforçar o caráter crítico da narrativa em relação à figura do General, reproduzindo uma das lendas não verificadas nos anais da história, aquela dos dois mil escravos que Bolívar chegou a ter no seu poder e que, ainda após as declarações feitas na sua famosa Carta de Jamaica (1815), que promulgava liberdade e igualdade nas nações independentes, permaneceram por ele mantidos na sua condição de subjugação.

A distorção da realidade histórica, demarcada na maioria de estudos historiográficos, por meio do exagero das cifras, das provocações e respostas irônicas, constituem uma das características que Aínsa (1991), teórico uruguaio do gênero romance histórico, atribui ao novo romance histórico latino-americano.

Da mesma forma, a heteroglossia, definida por Bakthin (1987) como a presença de distintos níveis de linguagem num mesmo ato discursivo, e que Menton (1993) aponta como uma das características dessa modalidade do romance histórico, faz-se presente no romance em relação à temática da subjugação racial:

-Lo que me gustaría realmente, Monteagudo, es que usted calle a ese negro de mierda porque si no lo silencio yo para siempre. ${ }^{17}$ (MOROTE, 2018, p. 48).

- ¡Qué te pasa negro de mierda! - le grita el Libertador. ${ }^{18}$ (MOROTE, 2018, p. 52).

Sí, aquí. No te hagas el tonto, negro de mierda. ${ }^{19}$ (MOROTE, 2018, p. 59).

¿No se ha dado cuenta de que no hay líderes en esta tierra, y de que todos los indios son truchimanes, ladrones, embusteros, falsos y no tienen ningún principio moral que los guíe?20 (MOROTE, 2018, p. 55). Esta molestia la adquirí en los Andes, me la deben haber contagiado los malditos indios. ${ }^{21}$ (MOROTE, 2018, p. 24).

A fineza e a parcimônia do falar do General se perdem na sua totalidade ao se referir aos negros e aos indígenas, o que ressalta, no texto, não só as distintas camadas ou níveis de linguagem, mas também as contradições internas no pensamento de Bolívar, que não considerava os negros e os indígenas dentro dos seus planos de emancipação.

está escrevendo uma biografia, não é? Pois saiba que fui um dos primeiros venezuelanos que tentou liberar seus escravos, o que aconteceu foi que os negros se negaram porque me amavam. Não, não faça essa cara de incredulidade, é verdade, Monteagudo. Afinal, após alguns anos, tive que forçá-los a se emancipar.

17 Tradução livre: O que eu gostaria realmente, Monteagudo, é que você cale esse negro de merda porque se não eu o vou silenciar para sempre.

${ }^{18}$ Tradução livre: Que acontece negro de merda! - gritou o Libertador.

${ }^{19}$ Tradução livre: Sim, aqui. Não se faça de bobo, negro de merda.

20 Tradução livre: Não percebeu que não há lideres nesta terra, e que todos os índios são truchimanes, ladrões, embusteiros, falsos e não possuem nenhum princípio moral que os guie?

${ }^{21}$ Tradução livre: Essa doença a adquiri nos Andes, devo ter sido contagiado pelos malditos índios. 
Para Mignolo (2007), que discute sobre a matriz colonial que persiste no nosso território desde a época da colonização, durante a época independentista das nações latino-americanas, los criollos (elite branca que se opunha ao governo das metrópoles, comumente descendentes de espanhóis nascidos na América), reproduziram "en los nuevos gobiernos independientes del Norte y del Sur la lógica de la colonialidad en desmedro de las poblaciones indígenas y de origen africano."22 (MIGNOLO, 2007, p. 71). Tal asseveração é retratada na diegese ficcional de Morote, na qual a personagem Bolívar leva o seu "racismo pouco dissimulado" (MOROTE, 2018, p. 55) a esferas políticas e militares, subjugando indígenas e negros sob o estandarte de uma independência criolla.

Decretos de Bolívar como a imposição ou manutenção de impostos aos indígenas pela sua raça, que constam nos registros históricos, são justificados pela personagem no romance, baseado na necessidade do desenvolvimento econômico das nações independentes, desenvolvimento que os indígenas, os negros e as classes mais baixas deveriam impulsionar com as suas vidas. Nos diálogos ficcionais do romance, Monteagudo questiona Bolívar sobre tais ações, mas Bolívar defende o seu posicionamento sem hesitar:

Sí, ya sé que San Martín suprimió ese tributo, pero no fue práctico. El tributo indígena representa el $40 \%$ del presupuesto del país. ¿De adónde piensa que voy a sacar el dinero para todo lo que hago en el Perú? [...] entienda que alguien tiene que cubrir las necesidades que tiene este país para progresar y a la vez mantener su libertad. [...] Por el momento no puedo dejar de cobrar esos tributos. Si las cosas mejoran, si la economía crece como espero, lo primero que haré será suprimir ese impuesto. Se lo prometo, Monteagudo. ${ }^{23}$ (MOROTE, 2018, p. 75 - grifo nosso).

O afã pelo desenvolvimento econômico e social, visando à modernidade que via nas nações europeias, é o cerne que movimenta as ações da personagem Bolívar. A criticidade do romance aponta para umas das principais falhas nos processos independentistas guiados pelos "heróis" libertadores, a manutenção do paradigma colonial, que, como aponta Mignolo (2007), é a cara oculta da modernidade. Segundo o estudioso argentino, "la historia de América Latina posterior a la independencia es la bistoria variopinta de la comunión voluntaria o involuntaria de las élites locales con la modernidad, que entrañó el empobrecimiento y la marginación de los pueblos indígenas, africanos y mestizos." "24 (MIGNOLO, 2007, p. 81).

\footnotetext{
22 Tradução livre: nos novos governos independentes do Norte e do Sul a lógica da colonialidad em detrimento dos povos indígenas e de origem africano.

${ }^{23}$ Tradução livre: Sim, já sei que San Martín eliminou esse tributo, mas não foi prático. O tributo indígena representa o $40 \%$ do pressuposto do país. De onde pensa que vou tirar o dinheiro para tudo o que faço no Peru? [...] entenda que alguém tem de cobrir as necessidades que este país tem para progredir e ao mesmo tempo manter a liberdade. [...] Por enquanto no posso deixar de cobrar esses tributos. Se as coisas melhorarem, se a economia cresce como espero, o primeiro que farei será eliminar esse imposto. Prometo para você, Monteagudo. (Grifo nosso)

${ }^{24}$ Tradução livre: A história da América Latina posterior à independência é a história diversificada da comunhão voluntária ou involuntária das elites locais com a modernidade, o que implicou o empobrecimento e a marginalização dos povos indígenas, africanos e mestiços.
} 
Um dos propulsores desse modelo moderno/colonial pós-independentista no Peru, que mantém a discriminação racial até os dias atuais, segundo a visão históricoficcional exposta em La visita de Bolivar (2018), é Simón Bolívar. Diante disso, o próprio romance vale-se da ironia como forma de carnavalizar a figura histórica para explanar fortes críticas às ações de Bolívar em relação às raças que ele considerava inferiores.

Tal processo de inversão de valores, no qual, como aponta Boves Naves (1997, apud. HESHMAT KASEM, 2018, s.p), "el débil se ríe del fuerte", baseia-se na dúvida histórica sobre a raça de Bolívar. É conhecido, na atualidade, que o Libertador não era um homem branco, como foi considerado por um longo tempo, mas ainda existem dúvidas a respeito do "nível de mestiçagem no seu sangue" e da "verdadeira cor" da sua pele. Do que se tem certeza, pelos registros históricos em cartas e outros documentos pessoais, é da antipatia que o Libertador tinha ao fato de não ser considerado "um homem branco".

Assim, na diegese ficcional, aproveita-se esse material histórico para carnavalizar a figura do Libertador. Vejamos um fragmento da conversação entre Monteagudo e Bolívar a respeito da temática racial:

- Yo, felizmente, ni una gota de indio.

- A mucha honra le puedo decir que mi madre fue mestiza. Dicen que en América el que no tiene de inga tiene de mandinga.

- Pues yo no tengo nada de indio ni de negro - replica con orgullo Bolívar - Claro, usted no lo sabrá distinguir, pero todos los artistas que me han pintado han sabido plasmar en sus cuadros mis facciones europeas.

Monteagudo ve que se abre una nueva oportunidad para poner al Libertador en su sitio:

- Es verdad, yo estoy negado para apreciar rasgos étnicos, sin embargo, creo haber visto en su residencia de Magdalena a un artista que lo pintaba con una tez oscura, y el cabello algo encrespado que podría sugerir unos ancestros... no sé...

- Ah, sí, ese pintor estaba mal de la vista, tuve que echarlo de mi casa. ${ }^{25}$ (MOROTE, 2018, $55)$.

No diálogo Bolívar nega qualquer influência indígena ou negra no seu sangre, mencionando os retratos que lhe são feitos por pintores famosos, nos quais suas "feições europeias" são destacadas. Diante disso, seu assessor alude a um episódio que, se bem não é corroborado pela historiografia, faz parte do imaginário histórico de países como Venezuela, Colômbia e Peru, entre outros: a ocasião em que um pintor colombiano retrata a figura de Bolívar com matizes das raças africanas negras - uma tez escura, um nariz maior e cabelos cacheados - ante o qual o General reage imediatamente, expulsando o artista da sua casa.

${ }^{25}$ Tradução livre: - Eu, felizmente, nem um pouco de índio. - Com muita honra posso dizer que minha mãe foi mestiça. Dizem que na América quem não tem de inga tem de mandinga. - Pois eu não tenho nada de índio nem de negro - aponta com orgulho Bolívar - Claro, você não saberá distinguir, mas todos os artistas que pintaram a minha figura souberam plasmar nos seus quadros as minhas feições europeias. Monteagudo percebe que se abre uma nova oportunidade para pôr o Libertador no seu lugar: - É verdade, eu estou negado para apreciar traços étnicos, contudo, creio ter visto na sua residência de Magdalena um artista que o pintava com uma tez escura, e o cabelo um pouco cacheado que poderia sugerir alguns ancestrais... não sei... 
Por meio de tal hibridismo histórico e ficcional, no qual o romance se vale dos aportes da história e das memórias do imaginário social, inverte-se a ordem do poder. Desenha-se Bolívar como um homem que nega suas raízes, discriminando sua própria raça em virtude dos ideais das elites brancas, às quais não pertencia, mas representava ativamente.

A problematização em relação à "pureza" do sangue de Bolívar não é novidade na ficção. Algumas obras, como o consagrado romance El General en su laberinto (1989), de Gabriel García Márquez, também abordam criticamente o assunto, inclusive fazendo referência aos quadros que "idealizavam" a figura do Libertador. O narrador da obra do literato colombiano, valendo-se da metanarrativa, admite que "[...] a medida que su [de Bolívar] gloria aumentaba, los pintores iban idealizándolo, lavándole la sangre, mitificándolo, hasta que lo implantaron en la memoria oficial con el perfil romano de sus estatuas." "26 (GARCÍA MÁRQUEZ, 1989, p. 184).

Contudo, o processo de desconstrução da figura de Bolívar na obra de García Márquez - o qual se restringe a humanizar a personagem e não a desconstrui-lo integramente ${ }^{27}-$, aponta para a "culpabilidade" dos historiadores, dos escultores e pintores nesse projeto idealizador, isentando o Libertador de qualquer interferência nesse processo. Já na obra de Morote (2018), que apresenta um discurso desconstrucionista mais enfático, embora imerso numa construção ficcional mais simples, aponta-se para Bolívar como principal agente na edificação dessa imagem idealizada que perdurou na história.

\section{LEITURAS PARALELAS}

Em contraste com esse processo de releitura e reconfiguração pelo qual passa a figura de Simón Bolívar e de suas ações na literatura hispano-americana, e que conta, como demonstramos, com uma ampla tradição que engloba desde narrativas exaltadoras e apologéticas - que corroboram o discurso idealizador e edificador da história -, a críticas, desconstrucionistas e desmistificadoras - que buscam justamente humanizar essa personalidade -, podemos estabelecer ainda inúmeros paralelos com produções híbridas escritas em todo o território americano que se voltam por meio ficção aos heróis eleitos pelo discurso institucionalizado, oferecendo perspectivas que transformam o nosso entendimento sobre o passado e a forma como foi postergado pela historiografia.

A exemplo do tratamento discursivo de Bolívar, tomemos do contexto brasileiro um herói consagrado que passa por uma dinâmica semelhante de exaltação/desconstrução: Dom Pedro I, personagem ficcional em As maluquices do

\footnotetext{
26 Tradução livre: [...] na medida que sua [de Bolívar] glória aumentava, os pintores o iam idealizando, lavando o seu sangue, mitificando-o, até que o implantaram na memória oficial com o perfil romano das suas estatuas.

27 Aprofundamos nessa temática no capítulo “Relecturas del pasado: El 'otro' Simón Bolivar de El General en su laberinto (1989) IN: El universo literario en la enseñanza de español como lengua extranjera en Brasil. (2018)
} 
Imperador (1927), de Paulo Setúbal, e em Galantes memórias e admiráveis aventuras do virtuoso conselheiro Gomes, o Chalaça (1994), de José Roberto Torero.

Noss romances citados, D. Pedro I também é recuperado sob distintas intenções ideológicas e submetido às mais variadas reconfigurações discursivas. Embora não seja ficcionalizado na mesma proporção que Bolívar, que recebe tratamento por escritores que extrapolam o contexto territorial no qual esteve envolvido em virtude de suas ações, Dom Pedro I ocupa um lugar igualmente ambíguo na historiografia nacional: é tido como herói, aquele que trouxe a independência à ex-colônia portuguesa, fundador da nação brasileira; como também é criticado por, nesse processo, colocar-se como defensor dos interesses dos grupos dominantes, especialmente do domínio português. Tais imagens, que seguem de um extremo ao outro, aparecem como substrato na composição ficcional dos romances citados que estabelecem um diálogo com o discurso fundador, com a imagem de D. Pedro como figura basilar do Império do Brasil e a extensão dos seus atos inaugurais.

No romance As maluquices do Imperador, publicado em 1927 pelo paulista Paulo Setúbal, são narradas as peripécias de D. Pedro, partindo desde a mocidade no Brasil, por ocasião da vinda da família Real portuguesa, até os momentos finais, quando falece aos 35 anos após lutar pelo direito da sua filha brasileira, Maria II, em ocupar o trono português, usurpado pelo seu tio D. Miguel. Ao longo das páginas somos postos diante de uma personagem ambígua, romântica por excelência, movida tanto por sentimentos nobres e generosos, por atitudes tolas e inconsequentes, quanto por extravagâncias amorosas e sexuais, em que aparece fortemente condicionado aos desejos e às vontades femininas. Embora se avultem na diegese tais contrastes, no desfecho da obra são eliminados os traços que poderiam confluir no rebaixamento de D. Pedro uma vez que alça status de cavalheiro e herói em razão da sua atuação na Guerra Civil Portuguesa (1828-1834).

Em vista disso, pela forma como o romance é arquitetado em sua estrutura formal e linguística - respeitando a linearidade cronológica do tempo da história, a reconstrução minuciosa da época passada, a presença de personagens de extração histórica conhecidas - e pelas intenções ideológicas expressas - de ensinar história ao leitor e de reforçar a mitificação do herói pela exaltação de suas ações em distintos episódios -, notamos que a narrativa de Setúbal não se distancia da visão tradicional do passado, pois não ressignifica, desmistifica ou desconstrói o olhar sobre os referentes utilizados, traço que corresponde às convenções da vertente tradicional da escrita híbrida de história e ficção conforme apontadas por Fernández Prieto (2003) e Fleck (2017).

Dessa maneira, pelas marcas destacadas, ainda que perpassem situações não convencionais a uma figura de estima, a obra As maluquices do Imperador mantém fidelidade aos referentes históricos e à manutenção da visão tradicional, modelo que também vemos reproduzido em torno da ficcionalização de Bolívar.

Por outro lado, em Galantes memórias e admiráveis aventuras do virtuoso conselheiro Gomes, o Chalaça (1994), de José Roberto Torero, introduz-se como foco narrativo do discurso a figura histórica de Francisco Gomes da Silva, amigo, secretário pessoal e 
alcoviteiro de D. Pedro I que, por sua relação próxima, oferece-nos uma imagem paródica e carnavalizada daquele que veio a se tornar o primeiro imperador do Brasil e dos episódios que marcaram os bastidores dessa história.

O romance estrutura-se como um diário, intercalado por um livro de memórias, ambos os textos ficcionais de autoria da personagem Chalaça, no qual narra-se os percalços da sua vida e os momentos relevantes que uniram a história brasileira e a portuguesa.

Conforme o relato que consta no prefácio, o registro que dispomos em mãos nada mais é do que esse documento original e que fora encontrado por um historiador pesquisador, o qual aparece no prefácio que abre o romance e em notas de rodapé ao longo do texto, que assina como "o autor" - aspecto que busca dar um sentido de verossimilhança aos fatos e imprime autorreferencialidade à obra. Este autor, contudo, não deve ser confundido com o autor da obra, isto é, o jornalista Torero. Em razão das marcas metaficcionais que aparecem nos paratextos citados, como no trecho do prefácio em que o narrador profere "Adianto ao leitor que adotei por método manter a estrita obediência à ordem dos apontamentos, o que inclui, além das anotações, cartas, reflexões e algumas memórias." (TORERO, 1994, p. 11), compreendemos que autor e narrador apenas compartilham o mesmo nome, sendo este narrador aquele que seleciona e organiza o texto.

Por não gozar de boa estima entre os historiadores tradicionais em virtude da natureza da sua relação com D. Pedro, Gomes da Silva foi relegado à margem da história. Na obra ficcional, a personagem busca, nos capítulos que se relacionam à sua autobiografia, fornecer a imagem de um sujeito distinto, o que contrasta com o conteúdo que encontramos no diário, este que passa pela manipulação do autor.

$\mathrm{Na}$ contramão dos registros oficiais, porém, o romance resgata esta personagem, que, como narrador autodiegético, ocupa lugar de privilégio na obra, pela qual são filtradas as ações protagonizadas por D. Pedro I.

Em uma das situações registradas, aparece nesse trecho biográfico a narrativa de como o Chalaça iniciou sua amizade com o jovem D. Pedro I. A personagem conta que, encontrando-se numa noite em um bar, cantando desafios - tipo de cantiga que os contadores se ofendem um ao outro - com um tal José Januário, dirigiu-se a um estranho para o qual recitou os seguintes versos: "Paulista é pássaro bisnau,/ Sem fé, nem coração./ É gente que se leva a pau/ A sopapo ou pescoção" (TORERO, 1994, p. 59). O estranho nada mais era que D. Pedro que, embora ameaçando o Chalaça, inicia com ele uma amizade inusitada após o Chalaça recompor os versos: "O Príncipe é pássaro real,/ Tem fé, tem coração./ O verdadeiro bisnau/ É aquele petralhão." (TORERO, 1994, p. 60). Este episódio é apontado pela personagem como o dia do seu nascimento e, portanto, ponto de início da sua autobiografia, achando desnecessário citar qualquer episódio anterior ao encontro com D. Pedro.

Além desse episódio, que pelas condições citadas, reveste-se de grande comicidade, o registro da relação com D. Pedro segue por linhas não convencionais. $\mathrm{Na}$ retomada de alguns eventos históricos recuperados por essa personagem de forte caráter picaresco, o Imperador recebe um tratamento paródico e carnavalizado, sendo 
destituído de seu caráter de "homem de mármore" e "herói nacional". Exemplo disso ocorre na ocasião que conta o Chalaça quando D. Pedro havia sido acometido de diarreia no trajeto a São Paulo, tendo que defecar diversas vezes, trecho no qual aparece um forte apelo ao baixo ventre e às necessidades escatológicas, ao que na sequência das ações, desorientado pela moléstia, proclama a independência do Brasil seguida pelo grito de Independência ou morte. Este episódio revela toda a ironia e comicidade da situação fundacional do Império brasileiro e entra em conflito com a popular imagem de D. Pedro I às margens do riacho Ipiranga, conforme retratado pelo artista Pedro Américo, na qual, nessa subjetivação imagética do passado, aparece como figura magnânima entre os demais.

Ao recuperar os eventos passados por vias não oficiais, além da presença da sobreposição de diferentes tempos históricos ao longo da diegese e a recorrência constante da paródia, da carnavalização, da intertextualidade e da polifonia como estratégia para desconstruir as figuras históricas consagradas, a obra de Torero revela traços do novo romance histórico latino-americano, modalidade que busca promover o enfrentamento com as versões hegemônicas do passado. A construção discursiva de D. Pedro aparece sob o foco desta premissa, que muito flerta com o riso, a ironia e o grotesco, fatores que na obra em tela contribuem com a desconstrução das imagens cristalizadas dos eventos históricos nos quais D. Pedro esteve envolvido e, ainda, na própria figura do imperador brasileiro.

Com base nesses dois exemplos que apresentamos sob o intuito de relacionar casos análogos de heróis da história que são submetidos a distintos tratamentos ficcionais, conforme segue com Bolívar na literatura hispano-americana e com D. Pedro na literatura brasileira, verificamos que o rebaixamento a que tais figuras são submetidas relaciona-se à tentativa de oferecer leituras críticas do passado ao público leitor que, muitas vezes, não se depara com essa possibilidade pelas veredas da historiografia oficial. Pela dinâmica que estas produções assumem, principalmente as modalidades mais recentes de romance histórico, a ficção constitui-se como mais um caminho alternativo para se conhecer prováveis outros aspectos de um passado sempre manipulado.

\section{CONSIDERAÇÕES FINAIS}

Os processos de releitura e reescrita da história pela ficção na América Latina se fundamentam na necessidade de explorar as visões periféricas e dar voz àqueles que foram silenciados no passado. Tais processos têm tido amplos frutos na produção de romances híbridos críticos, que destoam do discurso oficial e hegemônico da história, desconstruindo figuras que permaneciam idealizadas no imaginário latino-americano como as dos descobridores, colonizadores ou heróis nacionais -, enaltecendo e dando relevância a figuras não conhecidas ou que foram excluídas dos anais da história - como mulheres, negros e indígenas que participaram ativamente em causas sociais, militares ou políticas do nosso território -, revisitando e ressignificando episódios do passado fundamentais para a formação da nossa identidade híbrida e mestiça. 
Ao redor da figura de Simón Bolívar, como agente principal de um dos processos de transformação social, política e histórica da América Latina, o acervo de produções ficcionais híbridas transitou, até os dias de hoje, por distintas veredas. Obras enaltecedoras, humanizadoras, questionadoras e desconstrucionistas em distintos níveis foram publicadas em várias épocas e em diferentes regiões do continente e, também, fora do continente americano. Como expõe Cobo Borda (1989. p. 7), "al escribir sobre Bolivar cada cual, americano o español, proyectaba su Bolivar, poniendo en él lo que ya traía consigo. Simpatías, admiraciones, odios e ideales: su propia vida." 28

A nossa hipótese de leitura aqui apresentada é que, nos últimos anos têm surgido produções que desconstroem integralmente a figura heroica de Bolívar, isto é, abandonando qualquer tipo de construção de condescendência em relação aos feitos do General. Desse modo, os processos de humanização, desmistificação e desconstrução parcial, observados em obras como El General en su laberinto (1989), La ceniza del libertador (1987) ou En busca del Libertador (2010), intensificam-se, afastando-se dos beneplácitos oferecidos à figura de Bolívar.

Entre essas obras, totalmente desconstrucionistas, encontramos La carroza de Bolivar (2012) e La visita de Bolivar (2018). No presente texto buscamos abordar a segunda dessas obras, escrita pelo peruano Herbert Morote, denotando os processos narrativos e as estratégias escriturais pelos quais se produz o efeito da ressignificação do passado por meio da desmistificação da figura histórica.

Tal revisionismo histórico, observado na obra de Morote, tropeça, por momentos, no maniqueísmo, resumindo uma realidade tão complexa como aquela em que Bolívar e os outros independentistas participaram ativamente, a dois polos estáticos: os ditadores e os republicanos. Na obra, é verdade, existe uma pretensão histórica marcada, a de instaurar uma "verdade" por meio da destituição de outra, antes predominantes: Bolívar passa a ser o inimigo número um, após ter sido o Libertador.

Esse processo se efetua por meio de uma estrutura narrativa pouco complexa, abandonando o experimentalismo linguístico e formal, próprio dos romances históricos críticos da época áurea do novo romance histórico latino-americano, e adotando características dos romances históricos tradicionais, em questão de estrutura e desenvolvimento da diegese. Isso, no entanto, não reduz a carga crítica discursiva, que se impõe em toda a narrativa. Morote (2018) explora as prerrogativas da ficção, sustentando a diegese ficcional nas conversações privadas entre Bolívar e o seu assessor, Monteagudo, procedimento pelo qual a narrativa se adentra na subjetividade da personagem histórica, desvelando os supostos porquês das ações mais polêmicas do Libertador. Tal estrutura romanesca aproxima-se mais daquilo que Fleck (2017) classifica como a terceira fase do gênero: a mediadora

Analisada desde a perspectiva dos estudos decoloniais, entre os quais destacamos os pressupostos de Mignolo (2007) sobre a ferida colonial na América Latina, a reconfiguração ficcional de Bolívar no imaginário do nosso território, incentivada no romance de Herbert Morote, supõe um caminho para a descolonização ideológica. O

\footnotetext{
${ }^{28}$ Tradução livre: ao escrever sobre Bolívar cada um, americano ou espanhol, projetava seu Bolívar, pondo nele o que já trazia consigo mesmo. Simpatias, admirações, ódios e ideais: sua própria vida.
} 
romance apresenta a figura do Libertador como o cerne da corrupção, do racismo e do autoritarismo que se implantou nas nações independentes até os dias atuais. Tal configuração também ocorre com D. Pedro I na escrita crítica de Torero, que se estabelece diametralmente oposta a de Setúbal. Assim, a ficção abre novas possibilidades aos leitores para adentrar à construção discursiva sobre o passado, sem que a "verdade" seja o fator preponderante, mas, sim, as múltiplas possibilidades de se ressignificar aquilo que hoje é apenas discurso: o passado reconfigurado pela linguagem.

Levar ao espaço da sala de aula leituras desafiadoras como as que aqui expusemos

é uma via inquestionável de descolonização, ainda necessária em nossas sociedades latino-americanas.

\section{REFERÊNCIAS}

AÍNSA, F. La nueva novela histórica latinoamericana. Plural. 240. p. 82-85. México, 1991.

BAKHTIN, M. M. A cultura popular na Idade Média e no Renascimento: o contexto de François Rabelais. Trad. Yara Frateschi Vieira. São Paulo: HUCITEC, 1987.

CASALINO SEM, C. Centenario. Las celebraciones de la Independencia 1921-1924. Lima, Peru: Biblioteca Nacional del Perú, 2017.

COBO BORDA, J.G. Los nuevos Bolívares. Cuadernos Hispanoamericanos. Madrid, 1998, p. 7-25.

FERNÁNDEZ PRIETO, C. História y novela: poética de la novela histórica. Navarra: EUNSA, 2003.

FLECK, G. F. O Romance Histórico Contemporâneo de Mediação: entre a tradição e o desconstrucionismo - releituras críticas da história pela ficção. Curitiba: CRV, 2017.

GARCÍA MÁRQUEZ, G. El General en su laberinto. Bogotá: Editorial Oveja Negra, 1989.

HESHMAT KASEM, N. Desmitificación del personaje del Libertador en "La visita de Bolivar" de Herbert Morote. 2018. Disponível em: <https://www.herbertmorote.com/visitabolivar/critica-nozad-heshmat.pdf>. Acesso em: 17 jul. 2019.

GALVEZ, J. D. La figura histórica de Simón Bolivar en la literatura colombiana: De la humanización a su desmitificación. Editorial Académica Española (ONLINE), 2018.

MENTON, S. La nueva novela histórica de la América Latina: 1979-1992. México D. F: Fondo de Cultura Económica, 1993.

MIGNOLO, W. D. La idea de América Latina: la herida colonial y la opción decolonial. Trad. Silvia Jawerbaum; Julieta Barba. Barcelona, España: Editorial Gedisa, 2007.

MILTON, H. C. As histórias da história: retratos literários de Cristóvão Colombo. 1992. 189 f. Tese (Doutorado em Letras) - Universidade de São Paulo, São Paulo, 1992.

MOROTE, H. Bolivar Libertador y enemigo nº 1 del Perú. Lima, Perú: Editor SRL, 2007.

MOROTE, H. La visita de Bolivar. Lima, Perú: Biblioteca Nacional del Perú, 2018.

OVIEDO, R. R. Simón Bolivar como personaje literario y su transformación a partir de los tejidos de la verosimilitud en la novela y otras ficciones colombianas. Bogotá: Manuvo, 2015. 


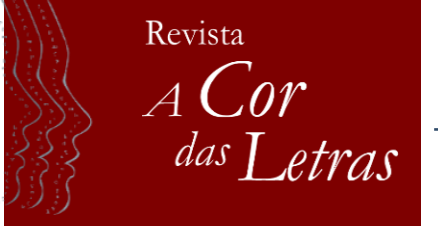

POSADA CARBÓ, E. 1910. La celebración del primer centenario en Colombia. Revista de Indias. 258. p. 579-590. España, 2013.

SETÚBAL, P. As maluquices do Imperador. São Paulo: Saraiva, 1927.

TORERO, J. R. Galantes memórias e admiráveis aventuras do virtuoso conselheiro Gomes, o Chalaça. São Paulo: Companhia das Letras, 1994.

Recebido em: 28/09/2019

Aprovado em: 07/11/2019

Publicado em: 19/12/2019 